\title{
Aspects of the Causative Morpheme -i- in Tonga (M64)
}

DOI: https://doi.org/10.47175/rielsj.v1i1.25

\section{| Khama Hang'ombe ${ }^{1, *} \mid$ Minyono Mwembe ${ }^{2}$ | Charton Siantumbu ${ }^{3}$ |}

\author{
1,2,3 Department of African \\ Languages and Literature, \\ University of Zimbabwe, \\ Harare, Zimbabwe \\ ${ }^{*}$ Corresponding Email: \\ hangombek@yahoo.com
}

\begin{abstract}
This paper examines the phonological behaviour of the causative morpheme - $i$ - in Tonga, using the Plateau and Valley Tonga varieties. It identifies the various segments in radical final positions of different verbal forms and seeks to establish how the introduction of the causative morpheme in their environment affects the segments. The paper finds that in some cases the morpheme induces phonological change to the segments preceding the morpheme, with more phonological 'activity' noted in Plateau Tonga. The influence of the morpheme identified in the study is that it induces fricativisation, palatalisation, or glottalisation to radical final segments of the verbs where it is introduced, depending on the nature the concerned segment. The conclusion drawn in the paper is that the influence of the morpheme is more pronounced in Plateau Tonga than in Valley Tonga.

KEYWORDS

Fricativisation; glottalisation; platalisation; Tonga
\end{abstract}

\section{INTRODUCTION}

This study examines the phonological behaviour of the causative morpheme -i- in Tonga (M64) and exposes that this morpheme, phonologically, behaves differently in the different contexts where it can be infixed. In order to successfully bring out the different phonological behaviours of the morpheme, the study uses the two main varieties of Tonga in Zambia: Plateau Tonga and Valley Tonga. In the light of Optimality Theory, it is shown in this study that the causative morpheme -i- triggers different phonological processes. In addition, the study shows that the particular realisation of the morpheme and the phonological process it triggers in each environment is dialect specific.

Tonga (M64) is a cross boarder language spoken in Zambia and Zimbabwe. However, the varieties the study focuses on are from Zambia. In Guthrie's (1948) classification of Bantu languages, Tonga is classified as belonging to Zone $\mathrm{M}$ in group 60 where it is the $4^{\text {th }}$ language with 3 dialects as follows: Leya, Toka, and Tonga. These dialects are spoken in Zambia. On the other hand, Doke (1959) identifies four Tonga dialects as follows: Plateau Tonga, Valley Tonga, We, and Totela. These varieties are also spoken in Zambia. Most of the Tonga varieties spoken in Zimbabwe, submitting as native speakers of Tonga well exposed to Tonga in both Zambia and Zimbabwe, mainly have similar phonological characteristics with Valley Tonga. In this study, examples are drawn from Plateau and Valley Tonga varieties because the difference in the phonological behaviour of the morpheme in question is easily noticeable in these varieties.

It is also worthy of note that the causative morpheme in Tonga take various forms as follows: - $\mathrm{i}-$, -esy- and -isy- (cf Carter, 2002:47-48). However, this study focuses on the -imorpheme because it is the one which has influence on the segments preceding it in certain environments. In Tonga, the causative morpheme - $\mathbf{i}$ - takes the shape of the front high 
vowel. According to Nkolola (2007) and Hyman (2003), in underlying representation, the front high vowel in Tonga has two variants: the ordinary front high vowel /i/, and the front super high vowel / $\mathrm{i} /$. Accordingly, it is highly probable that the shape of causative morpheme - $\mathrm{i}$ - in underlying representations possibly takes the two different shapes.

The data collection method used in this study is mainly introspection, though in all the cases a confirmation of the pronunciation of the verbal forms used as examples in examining the behaviour of the morpheme was sought from native speakers of each of the concerned varieties.

This study uses Optimality Theory (OT), a theory in which the observed language forms are thought to arise from most favourable satisfaction of the conflicting constraints. The main proponents of OT are Prince and Smolensky (1993) and McCarthy (2007). The former observes that OT models the grammar of a language as a system providing mappings from inputs to outputs. Thus, in OT the observed forms of a language arise from the interaction between conflicting constraints in the input. In this study, OT is used to show that when the causative morpheme -i- is infixed between the radical and the ending in Tonga, some phonological processes are blocked while others are triggered, depending on the variety of Tonga and regardless of the similarity in the morphological environment.

\section{RESEARCH METHOD}

This study examines the phonological behaviour of the causative morpheme -i- in Tonga (M64) and exposes that this morpheme, phonologically, behaves differently in the different contexts where it can be infixed. In order to successfully bring out the different phonological behaviours of the morpheme, the study uses the two main varieties of Tonga in Zambia: Plateau Tonga and Valley Tonga. In the light of Optimality Theory, it is shown in this study that the causative morpheme -i- triggers different phonological processes. In addition, the study shows that the particular realisation of the morpheme and the phonological process it triggers in each environment is dialect specific.

The data collection method used in this study is mainly introspection, though in all the cases a confirmation of the pronunciation of the verbal forms used as examples in examining the behaviour of the morpheme was sought from native speakers of each of the concerned varieties.

\section{CONSONANT, SEMI-VOWEL AND VOWEL PHONEMES IN TONGA}

Consonant and semi-vowel phonemes in Tonga are presented in Table 1 while vowel phonemes are presented in Table 2.

Table 1. Phonetic Chart of Tonga Consonants and Semi-vowels

\begin{tabular}{|c|c|c|c|c|c|c|c|c|}
\hline & $\begin{array}{l}\text { Bila- } \\
\text { bial }\end{array}$ & $\begin{array}{l}\text { Labio- } \\
\text { dental }\end{array}$ & Alveolar & $\begin{array}{l}\text { Post } \\
\text { alveolar }\end{array}$ & Palatal & Velar & $\begin{array}{l}\text { Labio- } \\
\text { velar }\end{array}$ & Glottal \\
\hline Plosive & $\mathrm{p} \quad \mathrm{b}$ & & $\mathrm{d}$ & & & $\mathrm{k}$ & & \\
\hline Nasal & $\mathrm{m}$ & & $\mathrm{n}$ & & $\mathrm{n}$ & y & & \\
\hline Fricative & $\beta$ & $\mathrm{v}$ & $\mathrm{z}$ & 3 & $\bar{j}$ & Y & & $\mathrm{h}$ \\
\hline Affricate & & & & t $\quad d s$ & & & & \\
\hline Lateral & & & 1 & & & & & \\
\hline Approximant & & & & & $\mathrm{j}$ & & $\mathrm{w}$ & \\
\hline
\end{tabular}

Adopted from Carter (2002:3-8) and Musale (2009:7) 
Table 2. Phonetic Chart of Tonga vowels

\begin{tabular}{|l|l|l|}
\hline & Front & Back \\
\hline High & i & u \\
\hline Mid & \multicolumn{1}{|c|}{ e } \\
\hline Low & & a \\
\hline
\end{tabular}

\section{RESULT AND DISCUSSION}

\section{Phonological influence of $-\boldsymbol{i}$ - in Plateau Tonga and Valley Tonga}

It is noted in this study that the causative morpheme $-i$ - either triggers a change in the manner of articulation or place of articulation on preceding phonemes in some morphological environments. It is also noted that there are cases where the morpheme triggers phonological change to a preceding segment in one variety but does not in the other variety (despite the morphophonological environment being similar). In cases where it triggers a change in manner of articulation, the influence points towards fricativisation in both varieties, while in cases where it triggers a change in the place of articulation, palatilisation and glottalisation can be noted in Plateau Tonga while in Valley Tonga no phonological change is noted.

\section{Manner of articulation change}

In this section it is shown that the causative morpheme - $\boldsymbol{i}$ - brings about a change in the manner in which non-fricative segments in radical final position are articulated; the morpheme causes a turbulent airflow (known as frication) in the articulation of the segments. In other words, non-fricative segments become fricatives due to the influence of the causative morpheme. This phonological process is known as fricativisation. It is shown in the study that the difference between the varieties is on the types of fricatives (from a place of articulation perspective) the segments change to.

\section{Fricativisation: Plateau Tonga}

In some morphological environments, the infixation of the causative morpheme -i- induces fricativisation to the preceding phoneme; the last consonant phoneme of the radical, as can be seen in examples (1) - (6):

1. sol-a [sola] 'try' $\rightarrow$ sol-i-a [sohja] 'cause to try'

2. low-a [lowa] 'bewitch' $\rightarrow$ low-i-a [lofja] 'cause to bewitch'

$$
\begin{aligned}
& {[\mathrm{l}] \rightarrow[\mathrm{h}]} \\
& {[\mathrm{w}] \rightarrow[\mathrm{h}]}
\end{aligned}
$$

3. lang-a [langa] 'look' $\rightarrow$ lang-i-a [lanfija] 'cause to look'

$[\mathrm{g}] \rightarrow[\mathrm{h}]$

4. lind-a [linda] 'wait' $\rightarrow$ lind-i-a [linfija] 'cause to wait'

$[\mathrm{d}] \rightarrow[\mathrm{h}]$

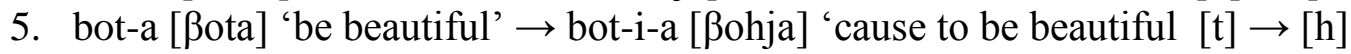

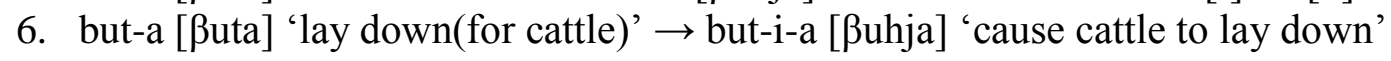

$$
[\mathrm{t}] \rightarrow[\mathrm{h}]
$$

In examples (1) - (6), just like in examples (7) - (12) the phonological situation can be summarised as follows:

$[$ non-fricative $] \rightarrow[$ fricative $] /{ }_{-}^{-i-}$

This means that non-fricative segments become fricatives before the causative morpheme i- . This observation is supported by Hyman (2003:56) who asserts that all 5 vowel-system 
Bantu languages, except Lengola "fricate" stops before /i/ and /u/. However, in Plateau Tonga, as can be seen from examples (1), (2), (7), and (8) it is not only the stops which become fricatives, rather, the lateral $/ 1 /$ and the approximant $/ \mathrm{w} /$ also fricativise.

It is also worthy of note that the change of the segments in examples (1) - (6) is in such a way that if the non-fricative segment undergoing the change is voiced, it changes to a voiced fricative and vice versa. For instance, in examples (1) - (4) the segments which undergo the change are voiced, and they change to the voiced fricative / $/$ /. On the other hand a voiceless non-fricative phoneme in examples (5) - (6) changes to a voiceless fricatives $/ \mathrm{h} /$.

In Plateau Tonga, non-fricative phonemes change to glottal phonemes when the causative morpheme is introduced, as can be seen in examples (1) - (6). Thus, it can be said that the optimal output when the causative morpheme $-\mathrm{i}$ - is introduced in a verbal form in Plateau Tonga are glottal fricatives.

\section{Fricativisation: Valley Tonga}

The infixation of the causative morpheme in verbal forms in Valley Tonga, just like in Plateau Tonga, also triggers fricativisation in some contexts. The difference between the two Tonga varieties is that while the optimal output in Plateau Tonga are glottal fricatives, in Valley Tonga it is the alveolar fricatives, as seen in examples (7) - (10) in which the verbal forms in examples (1) - (6) are repeated:

7. sol-a [sola] 'try' $\rightarrow$ sol-i-a [sozja] 'cause to try'

$$
[1] \rightarrow[z]
$$

8. low-a [lowa] 'bewitch' $\rightarrow$ low-i-a [lozja] 'cause to bewitch'

$[\mathrm{w}] \rightarrow[\mathrm{z}]$

9. lang-a [langa] 'look' $\rightarrow$ lang-i-a [lanzja] 'cause to look'

$[\mathrm{g}] \rightarrow[\mathrm{z}]$

10. lind-a [linda] 'wait' $\rightarrow$ lind-i-a [linzja] 'cause to wait'

$[\mathrm{d}] \rightarrow[\mathrm{z}]$

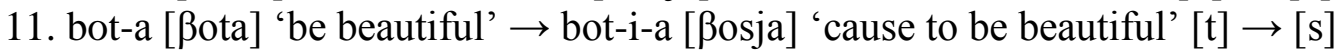

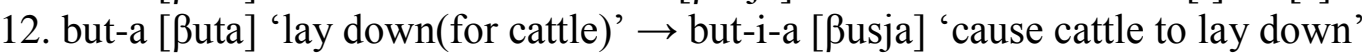

$$
[\mathrm{t}] \rightarrow[\mathrm{s}]
$$

In examples (7) - (12), as also seen in examples (1) - (6) if the segment undergoing the change is voiced, it changes to a voiced fricative and vice versa. The only difference is that while in examples (1) - (6) the concerned segments change to glottal fricatives, in examples (7) - (12) they change to alveolar fricatives. This shows that while the optimal output are glottal fricatives when the causative morpheme is introduced in Plateau Tonga, In Valley Tonga it is the alveolar fricatives.

\section{Place of articulation change}

In this section, it is shown that the causative extension morpheme triggers a change in the place of articulation to the nasal segments in radical final position in Plateau Tonga, while in Valley Tonga there is no phonological change to the nasal segments. Apparently, if a radical ends in a nasal segment in Tonga, the segment is always the alveolar nasal.

\section{Palatalisation: Plateau Tonga}

In Plateau Tonga, the voiced alveolar nasal /n/ in radical final position changes its place of articulation from the alveolar area to the palatal area when the causative morpheme $-\mathrm{i}$ - is introduced. This is demonstrated in examples (13) - (16):

13. bon-a [ßona] 'see' $\rightarrow$ bon-i-a [ßona] 'cause to see' $\quad[\mathrm{n}] \rightarrow[\mathrm{n}]$

14. aban-a [aßana] 'share' $\rightarrow$ aban-i-a [abana] 'cause to share' $\quad[\mathrm{n}] \rightarrow[\mathrm{n}]$

15. soban-a [soßana] 'play' $\rightarrow$ soban-i-a [sobana] 'cause to play' [n] $\rightarrow[n]$

16. zyan-a [fjana] 'dance' $\rightarrow$ zyan-i-a [hjana] 'cause to dance' $\quad[\mathrm{n}] \rightarrow[\mathrm{n}]$ 
In this case, the rule schemata can be summarised as follows:

$[\mathrm{n}] \rightarrow[\mathrm{n}] /$

This means that the voiced alveolar nasal becomes a palatal nasal before the causative morpheme -i-

On the basis of the examples (13) - (16), it can be said that the introduction of the causative morpheme - $\mathrm{i}$ - to a radical ending in an alveolar nasal in Plateau Tonga leads to the change in the place of articulation: instead of there being laminal or apical articulation for the nasal, due to the influence of the causative morpheme, it is produced in such a way that the tip of the tongue touches the hard palate. Thus, the alveolar nasal becomes a palatal nasal. In this case palatalisation ranked higher than the other constraints or competing possible phonological change, hence it is allowed.

\section{No palatalisation: Valley Tonga}

The introduction of the causative morpheme to radicals ending in the alveolar nasal does not trigger any change in the place of articulation to the nasal in Valley Tonga. The verbal forms in examples (13) - (16) are repeated as examples (17) - (20)

17. bon-a [ßona] 'see' $\rightarrow$ bon-i-a [ßonja] 'cause to play' $\quad[\mathrm{n}] \rightarrow[\mathrm{n}]$

18. aban-a [aßana] 'share' $\rightarrow$ aban-i-a [abanja] 'cause to share' $\quad[n] \rightarrow[n]$

19. soban-a [soßana] 'play' $\rightarrow$ soban-i-a [sobanja] 'cause to play' $[\mathrm{n}] \rightarrow[\mathrm{n}]$

20. zyan-a [zjana] 'dance' $\rightarrow$ zyan-i-a $>$ [zjanja] 'cause to dance' $[\mathrm{n}] \rightarrow[\mathrm{n}]$

The phonological situation in these examples can be summarised as follows:

$[\mathrm{n}] \rightarrow[\mathrm{n}] /$

This means that the alveolar nasal does not change even after the causative morpheme has been introduced in its environment in Valley Tonga.

From examples (17) - (20), it can be noted that the preferred output when the causative morpheme is introduced to radicals ending in the alveolar nasal in Valley Tonga is the same alveolar nasal, an apparent difference from what happens in Plateau Tonga.

\section{Glottalisation: Plateau Tonga}

In some cases the causative extension -i- triggers a change in the place of articulation of segments, without causing a change in the manner of articulation in Plateau Tonga. This is exemplified in (21) - (26):

21. cis-a [jisa] 'injure' $\rightarrow$ cis-i-a [jihja] 'cause to injure'

$[\mathrm{s}] \rightarrow[\mathrm{h}]$

22. yas-a [jasa] 'stab' $\rightarrow$ yas-i-a [jahja] 'cause to starb'

$[\mathrm{s}] \rightarrow[\mathrm{h}]$

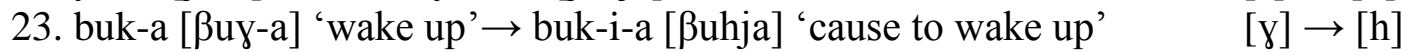

24. bwek-a [ßwey-a] 'complain' $\rightarrow$ bwek-i-a [bwehja] 'cause to complain' $[\gamma] \rightarrow[\mathrm{h}]$

25. wonz-a [wonza] 'bring down e.g fruits from a tree' $\rightarrow$ wonz-i-a [wonfja] 'cause to \begin{tabular}{l} 
bring down e.f fruits from a tree' $\quad[\mathrm{z}] \rightarrow[\mathrm{h}]$ \\
\hline '
\end{tabular}

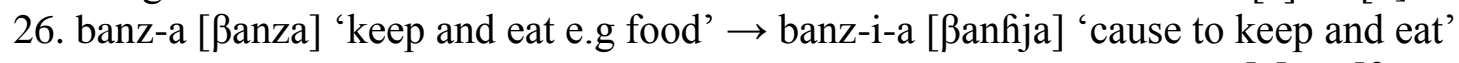

$[\mathrm{z}] \rightarrow[\mathrm{h}]$

The phonological situation in examples (21) - (26) can be summarised as follows:

[non-glottal fricative] $\rightarrow$ [glottal fricative]/ $-\mathrm{i}-$ 
This means that a non-glottal fricative segment becomes a glottal fricative before the causative extension $-\mathrm{i}-$.

In the examples above, $(21)-(26)$, the phonemes preceding the causative morpheme -iare either alveolar fricatives or the velar fricative which, due to the influence of the causative morpheme, change their places of articulation to the glottal area, hence they become glottal fricatives. Just as was observed with fricativisation, the phonological change in examples (1) - (12), if the input segment is voiced, it changes into a voiced glottal fricative and if it is voiceless, it changes into a voiceless glottal fricative. It can also be noted that the only fricatives involved in this phonological change in examples (21) (26) are alveolar fricatives /s/ and /z/), and the velar fricative / $\mathrm{\gamma} /$. This is because in Plateau Tonga radicals that end in fricatives either end in alveolar fricatives, the velar fricative, or the bilabial fricative. We explain what happens to radicals that end in thee bilabial fricative $/ \beta /$ (together with the rest of the bilabials) when it is precedes the causative morpheme -iin the next sub-section.

\section{No glottalisation: Valley Tonga}

The introduction of the causative morpheme to radicals ending in fricatives in Valley Tonga does not induce glottalisation. This is shown in examples (27) - (32):

27. cis-a [tyisa] 'injure' $\rightarrow$ cis-i-a [tisja] 'cause to injure'

$[\mathrm{s}] \rightarrow[\mathrm{s}]$

28. yas-a [jasa] 'stab' $\rightarrow$ yas-i-a [jasja] 'cause to stab

$[\mathrm{s}] \rightarrow[\mathrm{s}]$

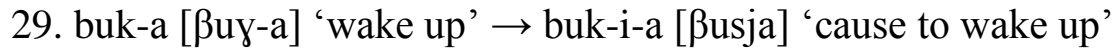

$[\mathrm{y}] \rightarrow[\mathrm{s}]$

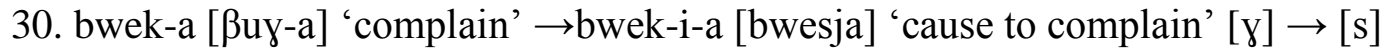

31. wonz-a [wonza] 'bring down e.g fruits' $\rightarrow$ wonz-i-a [wonzja] 'cause to bring down e.g fruits'

$[\mathrm{z}] \rightarrow[\mathrm{s}]$

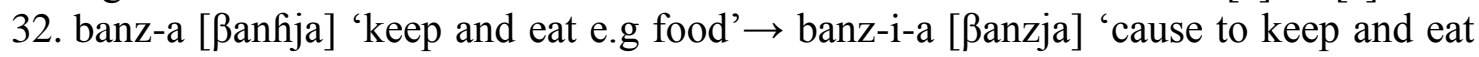
e.g food'

$[\mathrm{z}] \rightarrow[\mathrm{s}]$

In the examples (27) - (32), it can be seen that when the causative morpheme is added to verbal forms whose radical end in fricative segments, the segments do not undergo any phonological change in Valley Tonga Variety. Thus, while the preferred output segment when the causative morpheme is introduced to radicals ending in fricatives other than the bilabials fricative in Plateau Tonga are glottal fricatives, in Valley Tonga the input segments do not undergo any phonological change.

\section{No phonological change for bilabials for both Plateau Tonga and Valley Tonga}

There are cases when the causative extension morpheme -i- does not trigger any phonological change to the preceding phoneme in both Tonga varieties. This happens when the last phoneme of the radical is a bilabial as seen in examples (33) - (40):
33. simp-a [simpa] 'plant' $\rightarrow$ simp-i-a [simpja] 'cause to plant'
$[\mathrm{p}] \rightarrow[\mathrm{p}]$
34. cip-a [j(t)ipa] 'be cheap' $\rightarrow$ cip-i-a [j(tg)ipja] 'cause to be cheap' $[\mathrm{p}] \rightarrow[\mathrm{p}]$

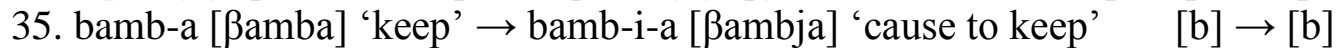

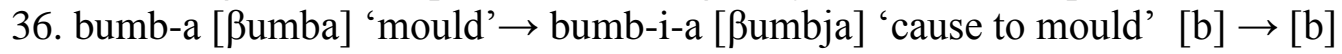
37. sum-a [suma] 'knit' $\rightarrow$ sum-i-a [sumja] 'cause to knit' $\quad[\mathrm{m}] \rightarrow[\mathrm{m}]$
38. lim-a [lima] 'cultivate' $\rightarrow$ lim-i-a [limja] 'cause to cultivate' $\quad[\mathrm{m}] \rightarrow[\mathrm{m}]$
39. zib-a [zißa] 'castrate' $\rightarrow$ zib-i-a [zißja] 'cause to castrate' $\quad[\beta] \rightarrow[\beta]$
40. zub-a [zußa] 'fish' $\rightarrow$ zub-i-a [zußja] 'cause to fish' $\quad[\beta] \rightarrow[\beta]$

As can be seen in examples (33) - (40), the bilabials in both varieties of Tonga do not undergo any phonological change when they precede the causative morpheme -i-. Taking a cue from what happens in most of the morphological environments, particularly with 
reference to Plateau Tonga when the causative morpheme is added to verbal forms; the situation in examples (33) - (40) may be cause for concern. The most likely question is, why is it that in other environments (especially in Plateau Tonga) the causative morpheme triggers phonological change to preceding segments but does not when the preceding segment is a bilabial? In attempting to provide an answer to this question, let us consider the articulation of the vowel whose shape the morpheme takes: in articulating the front high vowel, the tongue is raised towards the palate. On the other hand, the articulation of the bilabials requires that the lips come together, an act which can affect the height to which the tongue can be raised. In other words, it is possible that the influence of the morpheme gets neutralised by the closure of the mouth in articulating the bilabials.

It is highly probable, therefore, that the phonological realisation of the morpheme $-\mathrm{i}$ - in cases where it is preceded by bilabials is somewhat different from its realisation elsewhere, implying that the morpheme -i- has different realisations; it has allomorphs. This can be substantiated by the fact that the high vowel whose shape the causative morpheme takes, as stated already, has different phonological realisations as follows:

/i/

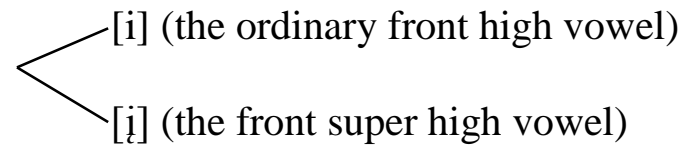

It can therefore, be argued that the phonological realisation of the morpheme -i- which triggers phonological change to the preceding segment takes the shape of the front super high vowel $/ \mathrm{i} /$ while that which does not takes the shape of the ordinary front high vowel /i/. Thus, the front super high vowel is more prevalent in Plateau Tonga than it is in Valley Tonga. This can be the possible plausible explanation as to reason why there is more phonological 'activity' when the causative morpheme is introduced to verbal radicals in most of the morphological environments in Plateau Tonga than one finds in Valley Tonga.

\section{CONCLUSION}

The causative morpheme - $\mathrm{i}$ - phonologically influences the final segments of radicals in different morphological environments in Tonga. From the examples and discussion in this paper, it can be concluded that the causative morpheme has more phonological influence on final radical segments in Plateau Tonga than in Valley Tonga. In Plateau Tonga, the morpheme induces a change in both the place of articulation and manner of articulation for the segments which precede it, in most cases. However, in Valley Tonga this morpheme only causes a change in the manner of articulation in certain environments.

In Plateau Tonga the morpheme can induce fricativisation, palatalisation, or glottalisation, depending on the type of the segment occupying the terminal position of a radical. In Valley Tonga, on the other hand, the morpheme can only trigger fricativisation. Thus, the morpheme is more active in Plateau Tonga than in Valley Tonga as far as inducing phonological change to segments preceding it is concerned.

It can also be noted that the nature of the change of the concerned segments as a result of the influence of the morpheme is 'cyclic' or 'closed', meaning if the input segment is voiced, the output segment is equally voiced. Correspondingly, if the input segment is voiceless, the output segment is equally voiceless.

\section{REFERENCES}

Carter, H. (2002). An Outline to Chitonga Grammar. Lusaka, Bookworld Publishers.

Cole, S. D. (1959). Doke's Classification of Bantu language. African Studies, 18(4):197-

213. 
Evans, V. and Green, M (2006). Cognitive Linguistics: An Introduction. Edinburgh: Edinburgh University Press.

Guthrie, M. (1948). The Classification of the Bantu Languages. London: Oxford University Press.

Hyman, L. (2003). Sound change, misanalysis, and analogy in the Bantu causative. JALL, 24: 55-90.

McCarthy, J. J. (2007). "What is Optimality Theory?" Language and Linguistics Compass. 93. Retrieved from https://scholarworks.umass.edu/linguist_faculty_pubs/93.

Musale, C.M.M. (2009). The Grammar of Compound Nouns in Tonga (Unpublished MA dissertation). Lusaka: University of Zambia.

Nkolola, M. (2007). An analysis of the applied, causative and passive verb extensions in Tonga. Unpublished PhD Thesis. Lusaka: University of Zambia.

Prince, A. and Smolensky, P. (1993). Optimality Theory: Constraint interaction in generative grammar. Rutgers Center for Cognitive Science Technical Report TR-2. 